\title{
Sistem Pendataan Penduduk Di Kantor Desa Ibarat
}

\author{
Andi Mariani ${ }^{\left.1^{*}\right)}$ \\ Sri Ariyanti Sabiku ${ }^{2 *}$ \\ Program Studi Teknik Informatika, Politeknik Gorontalo \\ email : andimariani@poligon.ac.id \\ email : sriariyantisabiku@poligon.ac.id
}

\begin{abstract}
Abstrak - Sistem Informasi pendataan penduduk di kantor desa Ibarat masih menggunakan sistem yang manual. Hal ini menimbulkan beberapa kendala dalam proses pengurusan dan pengolahan data penduduk. Terutama dalam ketidak cocokan data. Sering pula terjadi kendala terutama pada saat proses pendataan penduduk berdasarkan anggota keluarga, penduduk pindah, penduduk wafat, penduduk datang, penduduk lahir, dan pembuatan surat keterangan penduduk. Dari beberapa kendala diatas, maka dibuatlah rancangan suatu sistem informasi penduduk. Diharapkan sistem infomasi pendataan penduduk di kantor desa Ibarat, akan sangat membantu petugas dalam melakukan pendataan penduduk. Dimana sistem ini akan melakukan proses pengolahan data penduduk dan pendataan penduduk dengan cepat dan lebih optimal. Sistem yang dibangun menggunakan PHP dan MySQL sebagai database, dirancang dengan alur yang sederhana, sehingga dengan mudah digunakan oleh user. Dalam hal ini mengambil contoh di desa Ibarat, Kecamatan Anggrek, Kabupaten Gorontalo Utara. Hasil dari penenelitian ini adalah software Sistem Informasi Pendataan Penduduk di desa Ibarat, dan dapat disimpulkan bahwa dalam perancangan sistem informasi ini dapat memberikan kemudahan dan proses pengolahan data penduduk lebih optimal.
\end{abstract}

Kata kunci - Sistem Informasi, pendataan, Penduduk, PHP, MySQL.

\section{PENDAHULUAN}

Kantor desa Ibarat adalah salah satu instansi pemerintah yang memiliki tanggung jawab melakukan proses pendataan penduduk dan mengolah data penduduk, terutama dalam proses pendataan penduduk, berdasarkan anggota keluarga, penduduk pindah, penduduk wafat, penduduk datang, penduduk lahir, dan pembuatan surat keterangan penduduk [6].

Berdasarkan penelitian di kantor desa Ibarat proses pendataan penduduk, pengolahan data penduduk masih bersifat manual. Pengolahan data penduduk yang dihasilkan masih banyak kekurangan serta terjadi penumpukan data. Hal ini mengakibatkan masyarakat sering merasa sulit dalam proses pengurusan data penduduk yang dibutuhkan

\author{
Lian Potale ${ }^{3 *)}$ \\ Program Studi Teknik Informatika, Politeknik Gorontalo \\ 60111, email : lianpotale@gmail.com
}

karena pada saat datang ke kantor desa, data yang di minta belum dapat diproses langsung, bahkan masyarakat harus menunggu lama (satu minggu).

Dalam pengambilan informasi atau pendataan penduduk yang masih manual, pegawai harus datang ke rumah-rumah penduduk dengan membawa form data yang akan diisi oleh penduduk. Karena disebabkan terbatasnya sumber daya manusia dan banyaknya data yang dikelola[4], maka untuk meningkatkan pengelolahan data penduduk, diperlukan adanya pengembangan sistem pendataan, yang akan meminimalisir kesalahan dalam proses pengurusan data penduduk. Dimana komputer sebagai alat bantu dalam menyelesaikan proses yang berkaitan dengan pendataan penduduk [4].

Sistem informasi pendataan penduduk ini merupakan suatu sistem informasi yang mempunyai kemampuan dalam hal penyajian informasi secara cepat, tepat dan akurat, serta daya tampung yang besar dengan menangani dan mengolah data kependudukan yang ada di desa Ibarat. Dengan adanya informasi data penduduk ini, diharapkan dapat digunakan sebagai sarana penyimpanan data penduduk, dengan hanya mengakses data yang dibutuhkan oleh penduduk [5]. Melihat kelemahan dan kekurangan di desa Ibarat, diharapkan sistem informasi ini bisa memberikan solusi dalam pengolahan data penduduk. Sehingga dapat menghasilkan pelayanan yang optimal pada masyarakat.

\section{METODE PENELITIAN}

Pada bagian ini menjelaskan mengenai gambaran umum pada Sistem Informasi Pendataan Penduduk di Kantor Desa Ibarat.

\subsection{Analisa Sistem}

Analisa sistem merupakan penguraian dari suatu sistem yang utuh kedalam bagian-bagian komponennya dengan maksud untuk mengidentifikasi dan mengevaluasi permasalahan, pada bagian ini penulis mencoba menganalisa sistem yang sudah berjalan pada Sistem informasi pendataan penduduk di Kantor Desa Ibarat. 


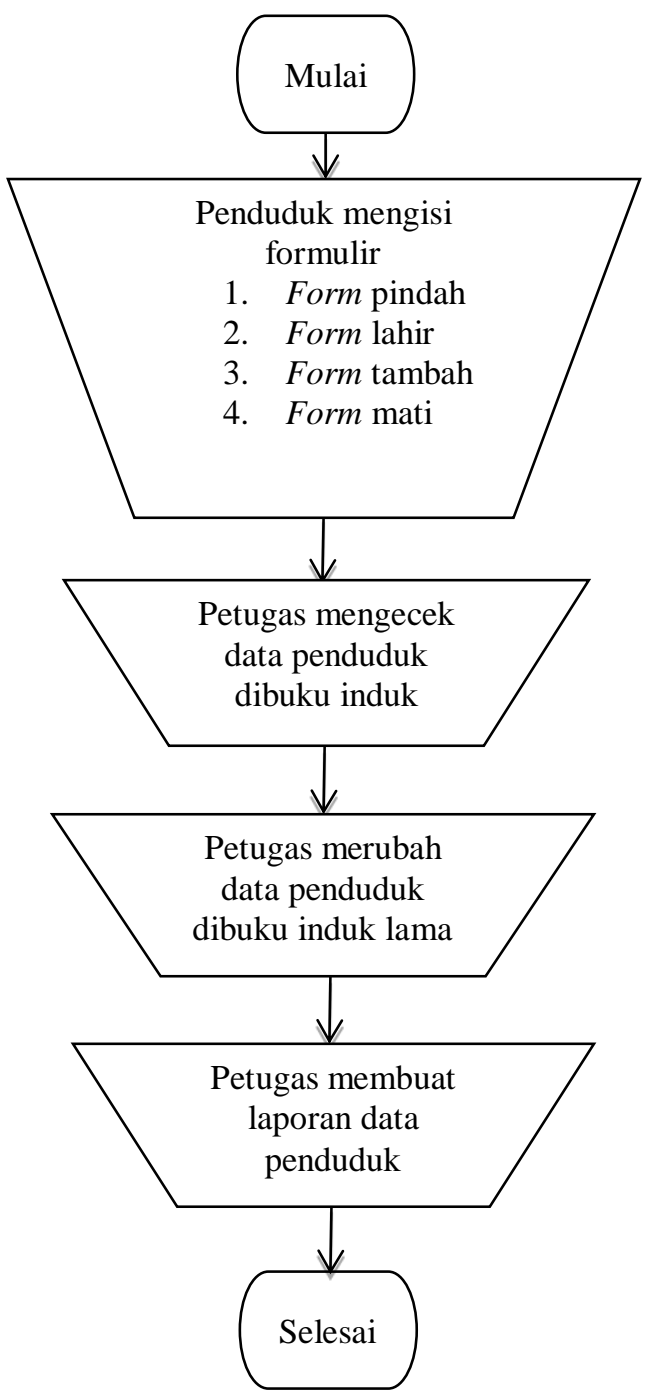

Gambar 2.1 Bagan Alir Analisis Sistem Yang Berjalan

Analisa bertujuan menganalisa sistem yang ada agar dapat dilihat kekurangan dari sistem itu sendiri, hal ini dilakukan untuk memperbaharui sistem yang ada. Adapun sistem yang berjalan pada sistem pendataan penduduk di kantor desa ibarat terlihat pada gambar 2.1 diatas.

\subsection{Tabel Relasi}

Tabel relasi merupakan hubungan yang terjadi antara suatu tabel dengan lainnyan yang mengiplementasikan hubungan antar objek nyata dan berfungsi untuk mengatur operasi suatu database. Sedangkan database adalah kumpulan informasi yang disimpan secara sistematik sehingga dapat diperiksa menggunakan suatu program untuk mendapatkan informasi.

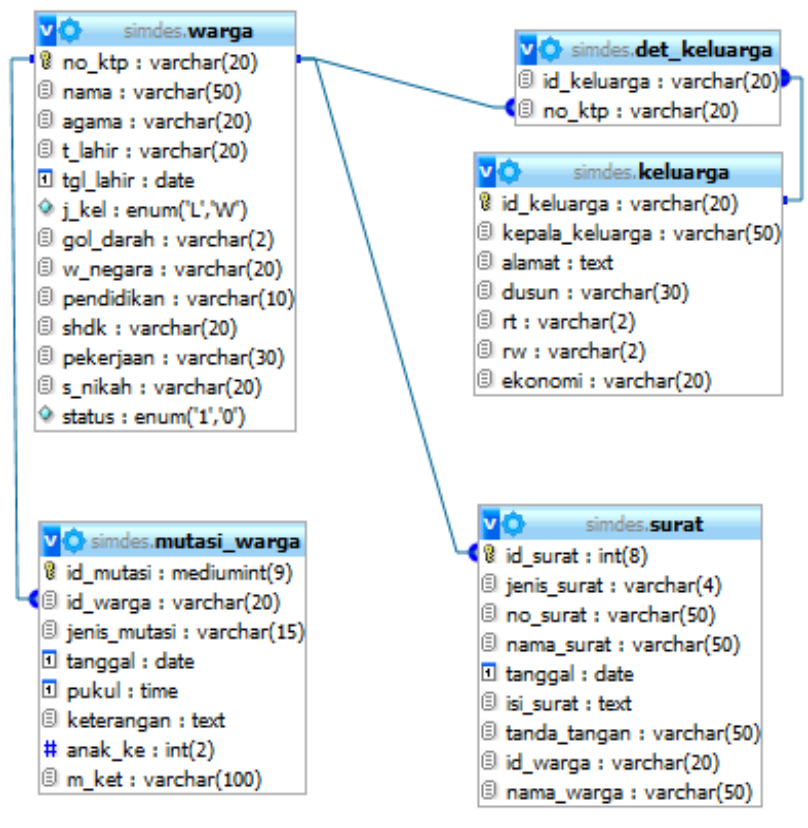

Gambar 2.2 Tabel Relasi

\section{HASIL DAN PEMBAHASAN}

\subsection{Implementasi program}

\subsubsection{Halaman Menu Utama}

Halaman menu utama merupakan tampilan utama pada saat user mengakses masuk URL addres sistem ini. Pada menu utama tersedia beberapa menu yang bisa digunakan untuk mengakses file yaitu daftar penduduk, daftar keluarga, daftar kematian, daftar lahir, daftar penduduk datang, daftar penduduk pindah, daftar surat, laporan penduduk, dan keluar.

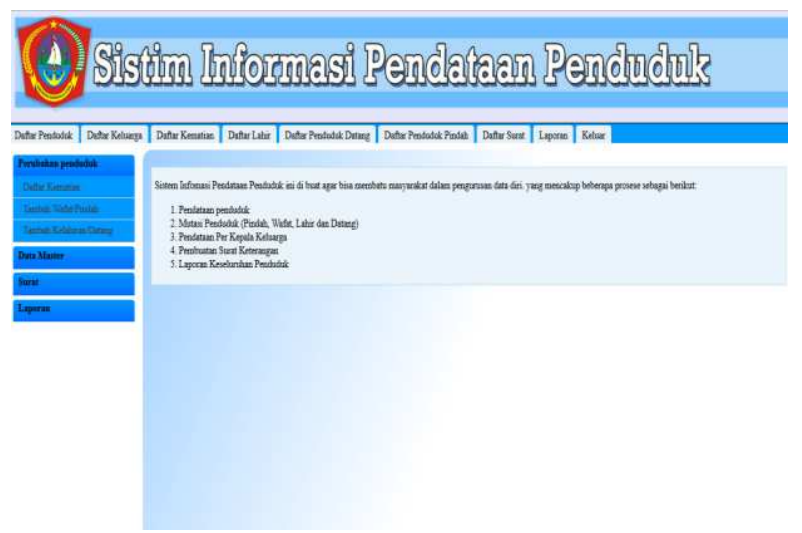

Gambar 3.1 Menu Utama

\subsubsection{Tampilan Menu form data tambah penduduk}

Pada menu form data penduduk adalah menu yang akan digunakan untuk menambahkan data penduduk dan semua field wajib diisi. 


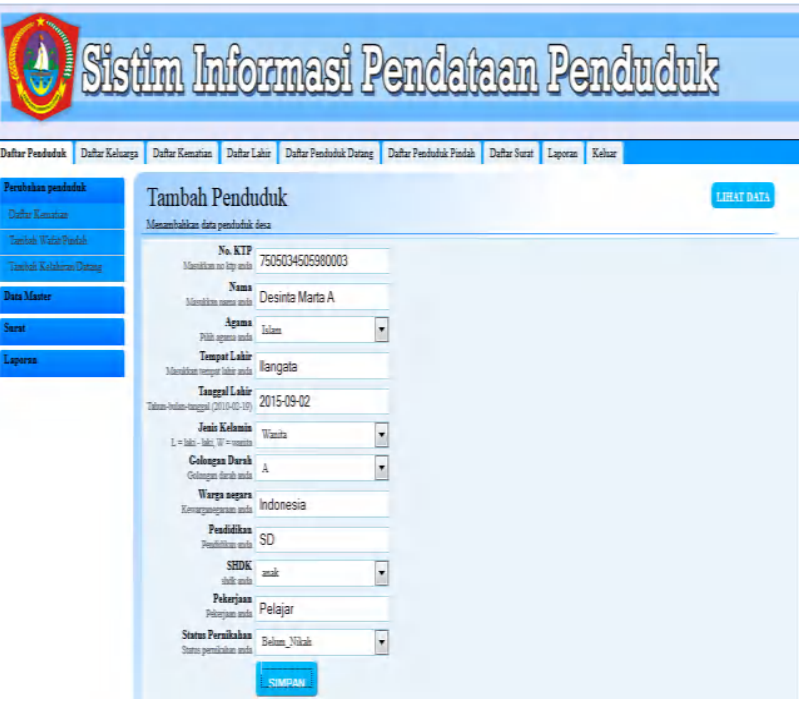

\section{Gambar 3.2 Menu form data penduduk}

\subsubsection{Tampilan Menu daftar data penduduk}

Pada menu form daftar penduduk adalah menu yang menampilkan seluruh data penduduk yang telah di inputkan pada form tambah data penduduk. Pada tampilan daftar data penduduk user bisa merubah langsung record yang ada didalam field data, serta terdapat juga kolom pencarian data penduduk berdasarkan no ktp dan nama. Sehingga ketika user mencari nama penduduk yang dimaksud dapat secara cepat dan tepat ditemukan pada proses pencariannya. Tampilan menu daftar data penduduk ditunjukan pada gambar 3.3

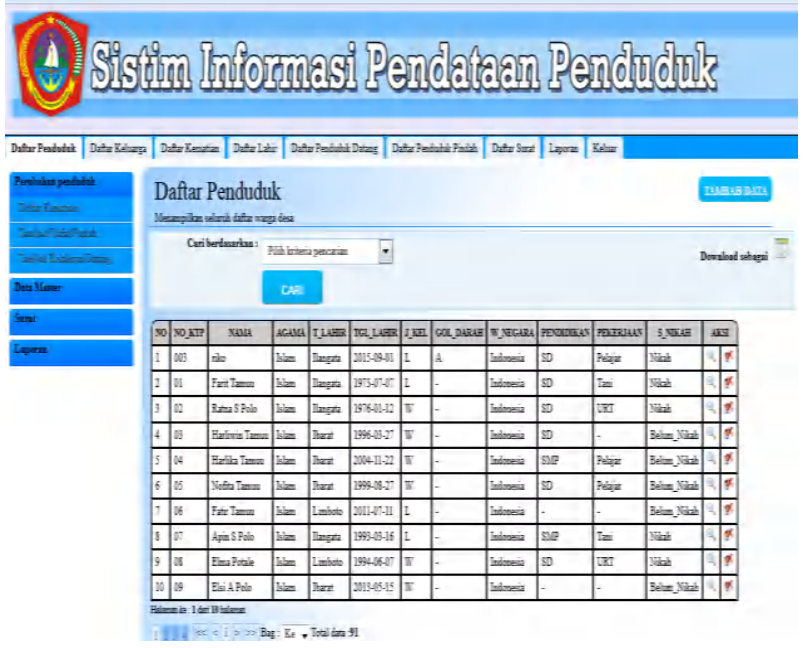

Gambar 3.3. Menu daftar data penduduk

\subsubsection{Tampilan detail data penduduk}

Tampilan detail data penduduk hanya menampilkan detail data penduduk yang ada pada daftar penduduk. Tampilan detail data penduduk di tunjukan pada gambar 3.4.

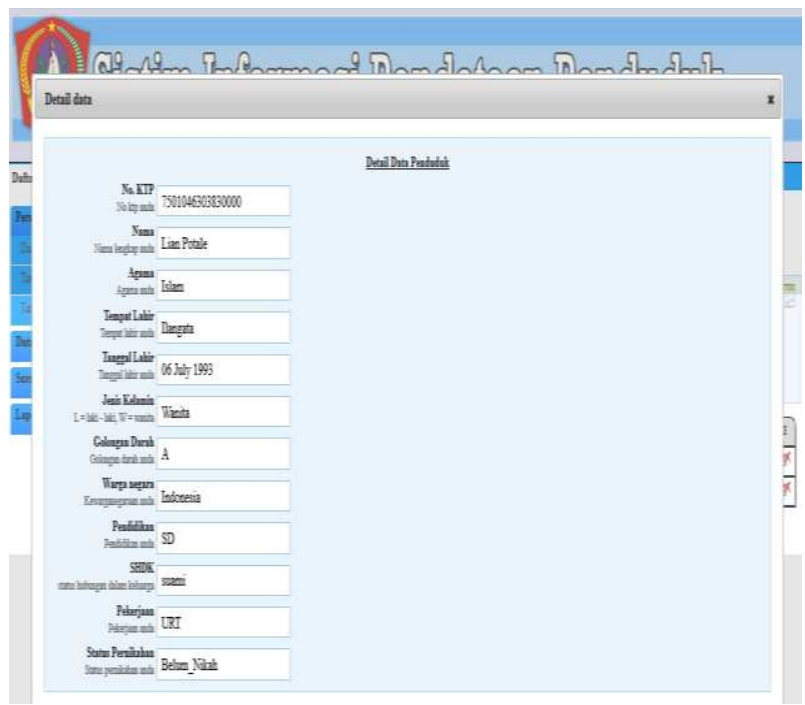

Gambar 3.4. Tampilan detail data penduduk

\subsubsection{Tampilan Menu form data tambah keluarga}

Pada menu form data keluarga adalah menu yang akan digunakan untuk menambahkan data keluarga dan semua field wajib diisi. Pada form ini terdapat field anggota keluarga yang berfungsi untuk menginputkan data keluarga dalam KK. Tampilan menu form data tambah penduduk ditujukan oleh gambar 3.5.

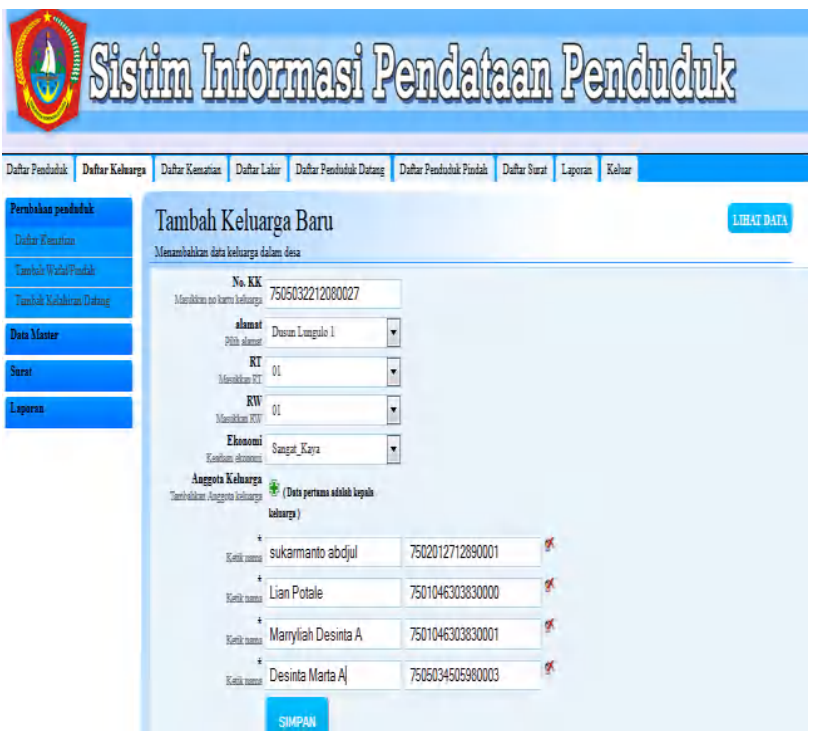

Gambar 3.5 Menu form data tambah keluarga

\subsubsection{Tampilan form surat keterangan}

Pada form surat keterangan user hanya menginputkan nama penduduk pada field nama atau nama pemohon maka akan terisi secara otomatis field yang selanjutnya kecuali field keterangan. Tampilan form surat keterangan di tujukan oleh gambar 3.6. 


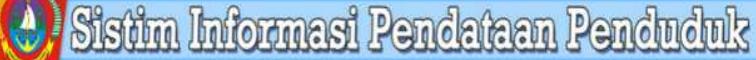

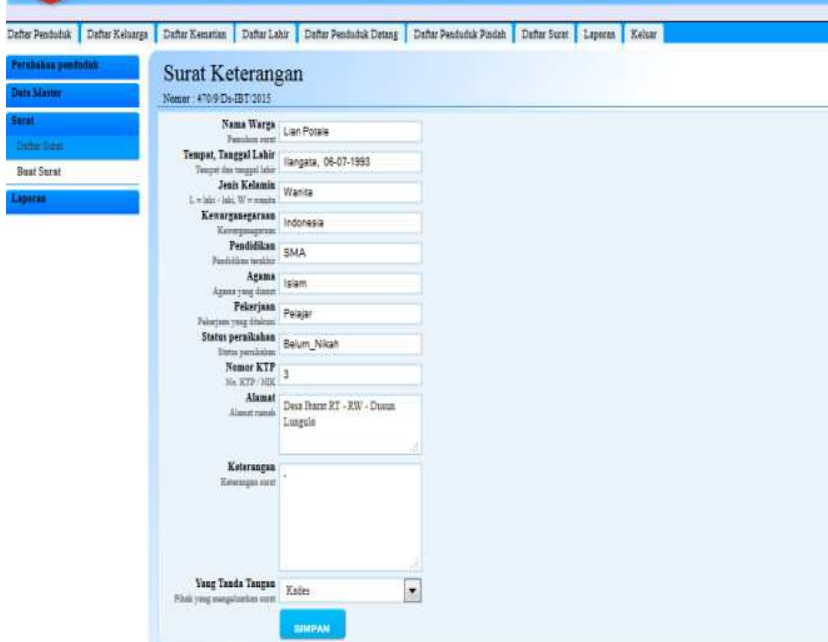

Gambar 3.6 Tampilan form surat keterangan

\subsubsection{Tampilan form surat kelahiran}

Pada tampilan surat keterangan kelahiran adalah tampilan surat keterangan kelahiran yang di inputkan user. Tampilan form surat keterangan kelahiran di tujukan oleh gambar 3.7

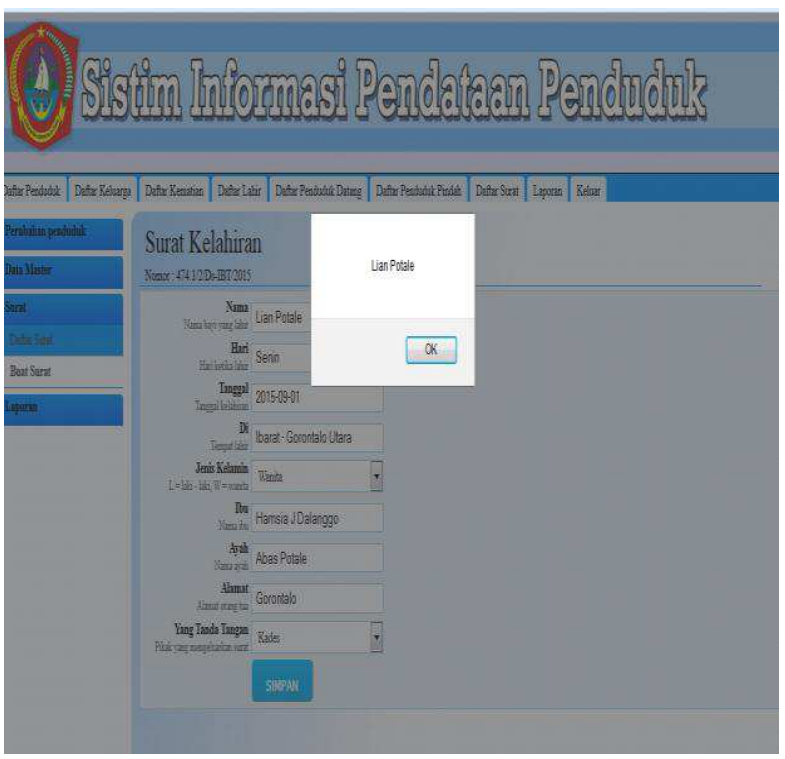

Gambar 3.7 Tampilan form surat kelahiran

\subsubsection{Tampilan surat kelahiran}

Tampilan surat kelahiran adalah format surat yg sudah jadi dan siap di cetak. Tampilan surat kelahiran di tujukan oleh gambar 3.8.

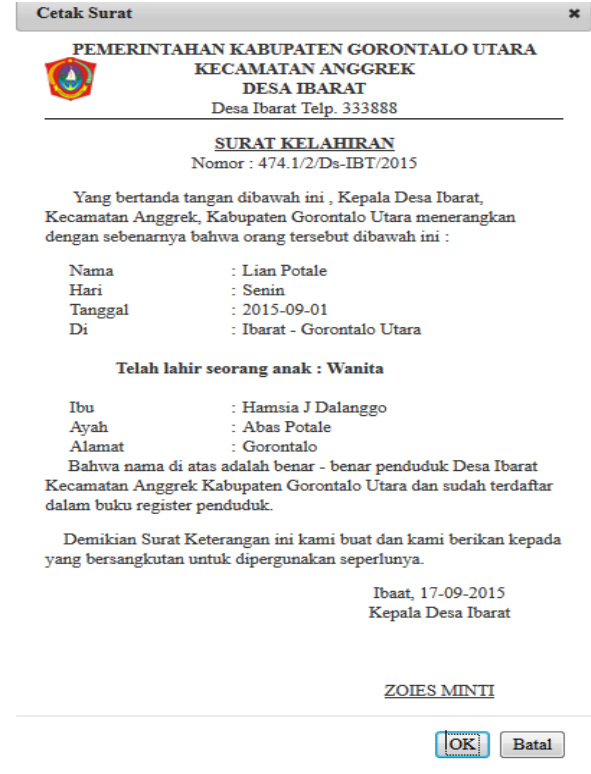

Gambar 3.8 Tampilan surat keterangan kelahiran

\subsubsection{Tampilan form surat kematian}

Pada tampilan surat keterangan kematian adalah tampilan surat kematian yang di inputkan user. Tampilan form surat keterangan kematian di tujukan oleh gambar 3.9

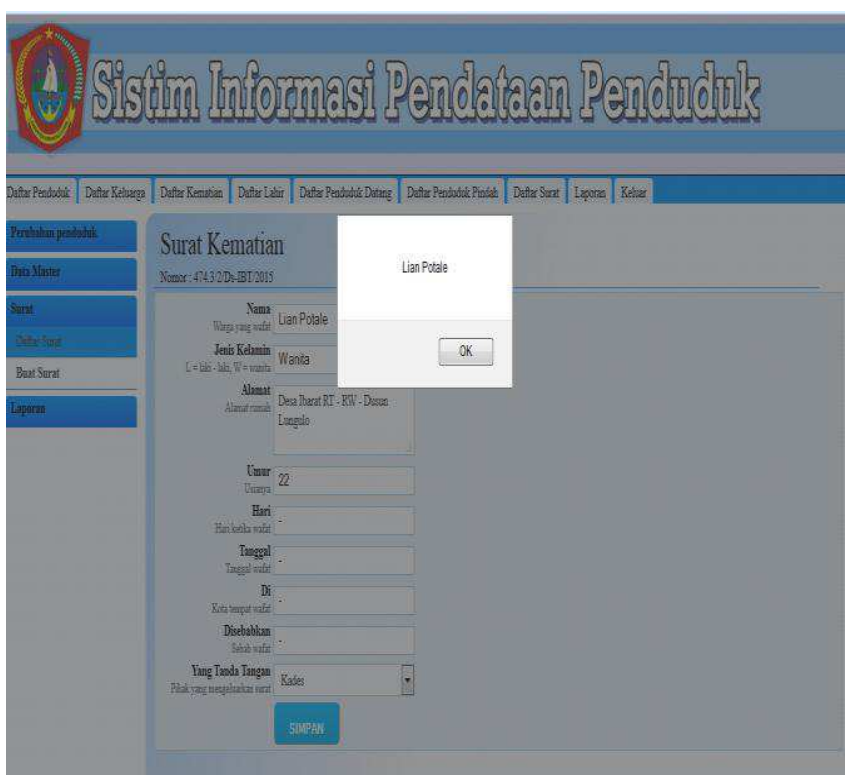

Gambar 3.9 Tampilan form surat kematian

\subsection{Tampilan surat kematian}

Tampilan surat kematian adalah format surat yg sudah jadi dan siap di cetak. Tampilan surat kematian di tujukan oleh gambar 3.10 . 


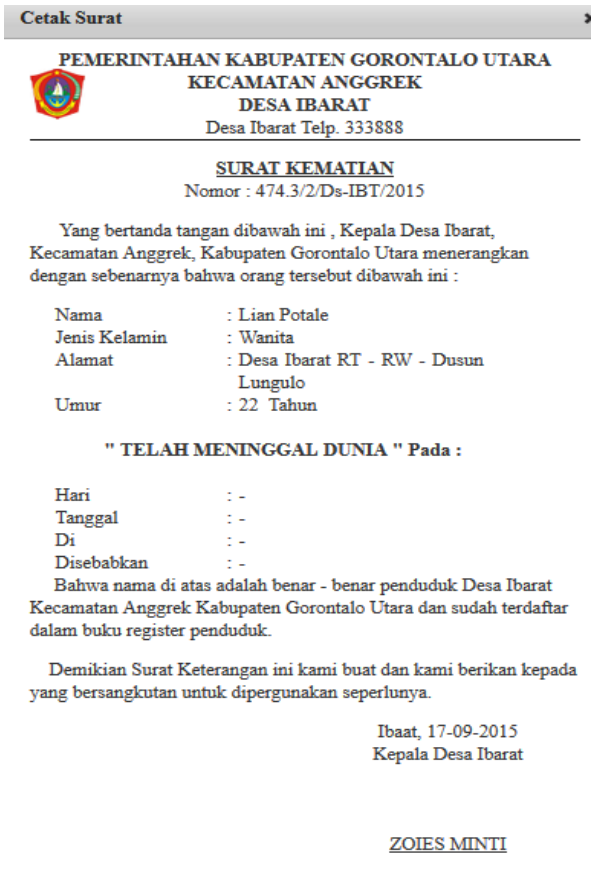

Gambar 3.10 Tampilan surat kematian

\subsection{Tampilan Menu Daftar Surat}

Pada tampilan menu daftar surat adalah menu yang hanya menampilkan seluruh daftar surat yang telah dibuat sebelumnya dan bisa dilihat,namun pada daftar surat ini user tidak bisa mengedit form surat. Tampilan menu daftar surat di tujukan oleh gambar 3.11.

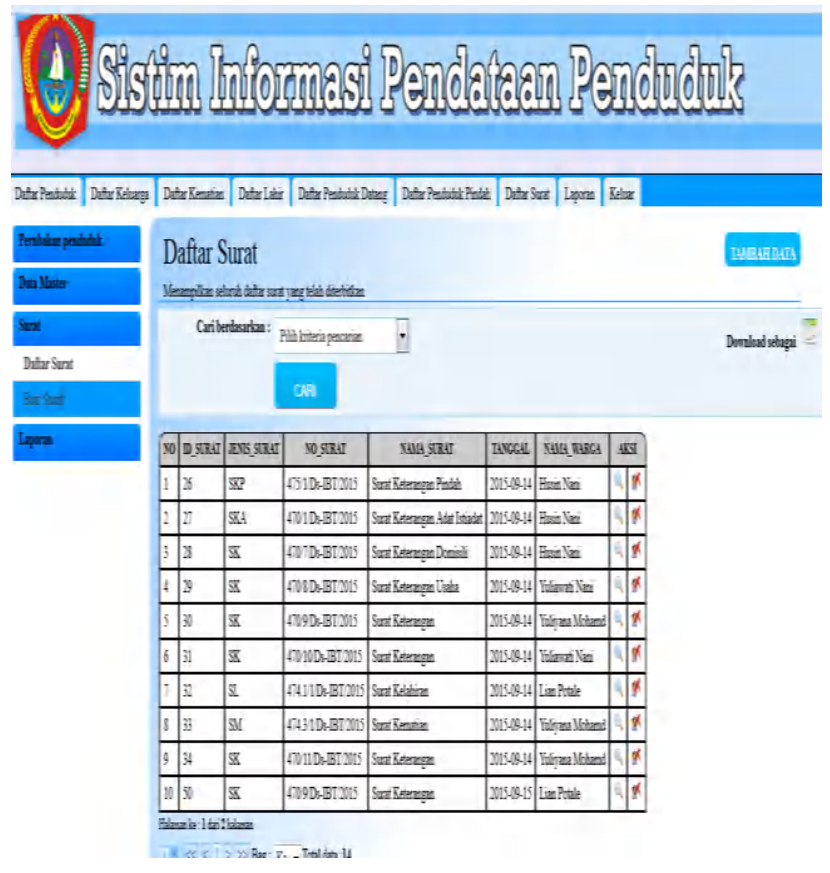

Gambar 3.11 Tampilan daftar surat

\section{KESIMPULAN}

\subsection{Kesimpulan}

Setelah melalakukan rancangan dan menguji aplikasi sistem pendataan penduduk di Kantor Desa Ibarat, maka pada bab ini penulis akan memberikan kesimpulan dan gambaran untuk pengembangan sistem selanjutnya, di harapkan agar dapat membantu dalam pengembangan sistem informasi pendataan penduduk di Kantor Desa Ibarat. Berdasarkan sistem yang di bangun penulis, maka dapat di simpulkan bahwa :

1. Setelah pengujian sistem yang di lakukan dengan menginputkan jumlah data sebanyak 100 data bisa menghemat waktu kurang lebih 20 menit, dibandingkan dengan proses pengelolaan data penduduk yang masih menggunakan sistem yang berjalan dan memerlukan waktu lama.

2. Memanfaatkan dan menggunakan sistem komputer yang sudah dirancang sangat membantu dalam proses pengolahan data dan memperoleh informasi. seperti halnya sistem informasi pendataan penduduk di Kantor Desa Ibarat yang telah di rancang, agar dapat membantu proses pengolahan, pencarian dan pengurusan data peduduk.

\subsection{Saran}

Dari analisis pengujian yang telah di lakukan terhadap sistem yang di buat penulis menyadari perlu pengembangan yang lebih lanjut, agar aplikasi ini dapat menjadi aplikasi yang lebih baik sehingga dapat mempermudah pihak Kantor Desa dalam proses pengolahan data penduduk.

1. Pengembangan selanjutnya, di harapkan sistem ini mampu di kembangkan menjadi lebih efisien.

2. Pengembangan selanjutnya, di harapkan sistem ini mampu di kembangkan menjadi terintegrasi dengan Kantor Desa, Kantor Camat, dan Kantor CAPIL, sehingga dapat memberikan informasi dan mengolah data kepedukan yang mampu menghasilkan sebuah data dalam proses pembuatan Kartu keluarga, Akta kelahiran, dan Pengurusan E-KTP.

3. Dengan perkembangan teknologi saat ini dimana setiap data terintegrasi satu sama, maka di harapkan sistem ini bisa memanfaatkan perangkat mobile/smartphone.

\section{DAFTAR PUSTAKA}

[1] Hartono., 2007, “Geografi: Jelajahi Bumi dan Alam Semesta”, CV Citra Praya Komp. Cibolerang Indah Blok E No. 52, Bandung 40224

[2] Pratama, I Putu Agus Eka.,2014., "Sistem Informasi dan implementasinya", Informatika Bandung, Bandung. 